\title{
Interaction of Stoned and Synaptotagmin in Synaptic Vesicle Endocytosis
}

\author{
Tim Fergestad and Kendal Broadie \\ Department of Biology, University of Utah, Salt Lake City, Utah 84112-0840
}

The Drosophila dicistronic stoned locus encodes two distinctive presynaptic proteins, Stoned A (STNA) and Stoned B (STNB); STNA is a novel protein without homology to known synaptic proteins, and STNB contains a domain with homology to the endocytotic protein AP50. Both Stoned proteins colocalize precisely with endocytotic proteins including the AP2 complex and Dynamin in the "lattice network" characteristic of endocytotic domains in Drosophila presynaptic terminals. FM1-43 dye uptake studies in stoned mutants demonstrate a striking decrease in the size of the endo-exo-cycling synaptic vesicle pool and loss of spatial regulation of the vesicular recycling intermediates. Mutant synapses display a significant delay in vesicular membrane retrieval after depolarization and neurotransmitter release. These studies suggest that the Stoned proteins play a role in mediating synaptic vesicle endocytosis. We have documented previously a highly specific syn-

The rapid recycling and biogenesis of synaptic vesicles (SVs) is essential for sustained neurotransmission. The classical model for SV turnover uses an endosomal sorting/biogenesis mechanism, thought to occur away from the active zone (Heuser and Reese, 1973, 1981). Another model suggests a direct mechanism for recycling complete SVs from the plasma membrane immediately adjacent to the active zone (Ceccarelli et al., 1973; Ceccarelli and Hurlbut, 1980), eliminating the requirement for a sorting endosome (Murthy and Stevens, 1998). Ultrastructural evidence from Drosophila supports both models, with a fast recycling mechanism near the active zone and a slower, distant endosome-mediated pathway (Koenig and Ikeda, 1989, 1996). Both of these mechanisms likely coexist within the same terminal, with the endosomal pathway preferentially used under demanding recycling conditions (Koenig and Ikeda, 1996; Palfrey and Artalejo, 1998). Regardless of the pathway, all recycling mechanisms must provide the machinery to generate architecturally precise SVs containing the exact complement of lipids and proteins required for neurotransmitter filling, targeting, and regulated fusion.

Recent work has suggested that specialized machinery exists for the recruitment and recycling of specific vesicular proteins.

\footnotetext{
Received Oct. 4, 2000; revised Nov. 16, 2000; accepted Nov. 22, 2000.

This study was supported by National Institutes of Health Grant GM54544 and an EJLB scholarship to K.B. and by National Institutes of Health Developmental Biology Training Grant 5T32 HD07491 to T.F. We thank Marie Phillips for communicating unpublished results. We are grateful to $\mathrm{M}$. Gonzalez-Gaitan for providing $\alpha$-Adaptin antibody and T. Littleton for the UAS-SytI construct. Special thanks to Michael Bastiani for extensive confocal use and Jeff Rohrbough for valuable comments on this manuscript.

Correspondence should be addressed to Dr. Kendal Broadie, Department of Biology, University of Utah, 257 South 1400 East, Salt Lake City, UT 84112-0840. E-mail: broadie@biology.utah.edu.

Copyright (C) 2001 Society for Neuroscience 0270-6474/01/211218-10\$15.00/0
}

aptic mislocalization and degradation of Synaptotagmin I in stoned mutants. Here we show that transgenic overexpression of Synaptotagmin I rescues stoned embryonic lethality and restores endocytotic recycling to normal levels. Furthermore, overexpression of Synaptotagmin I in otherwise wild-type animals results in increased synaptic dye uptake, indicating that Synaptotagmin I directly regulates the endo-exo-cycling synaptic vesicle pool size. In parallel with recent biochemical studies, this genetic analysis strongly suggests that Stoned proteins regulate the AP2-Synaptotagmin I interaction during synaptic vesicle endocytosis. We conclude that Stoned proteins control synaptic transmission strength by mediating the retrieval of Synaptotagmin I from the plasma membrane.

Key words: Drosophila; stoned; synaptotagmin; synapse; synaptic vesicle; endocytosis

For example, the v-SNARE Synaptobrevin is specifically retrieved via interaction with adaptor protein AP180 (Nonet et al., 1999). Another key target is Synaptotagmin I, a putative $\mathrm{Ca}^{2+}$ sensor for SV exocytosis and also a protein implicated in SV endocytosis (Jorgensen et al., 1995; Reist et al., 1998; von Poser et al., 2000), which has been proposed to be retrieved via interaction with the AP2 complex (Zhang et al., 1994). We have shown previously that Synaptotagmin I is specifically mislocalized and degraded in Drosophila stoned mutants, suggesting that the Stoned proteins may also play a role in Synaptotagmin I recycling (Fergestad et al., 1999). The dicistronic stoned locus encodes two proteins, Stoned A (STNA), a novel protein, and Stoned B (STNB), a protein with homology to endocytotic protein AP50 (Andrews et al., 1996). Both STNA and STNB directly bind Synaptotagmin I (Phillips et al., 2000). Both stoned and synaptotagmin mutants have fewer, structurally abnormal SVs, suggesting that these proteins may function in a common mechanism during SV recycling (Reist et al., 1998; Fergestad et al., 1999). These studies suggest that the Stoned proteins may be required for the targeted retrieval of Synaptotagmin I during SV recycling, a function similar to that of the adaptor proteins.

In this study, we focus on the mechanistic function of the Stoned proteins in the presynaptic terminal and directly investigate Stoned-Synaptotagmin I interactions. First, we show that both Stoned proteins colocalize with the subcellular endocytotic network within synaptic boutons. Second, we use dye-imaging studies to implicate Stoned directly in endocytosis mechanisms at the plasma membrane. Third, we transgenically overexpress Synaptotagmin I in stoned mutant backgrounds and show that this rescues both lethality and the causal endocytotic defect at the synapse. These studies suggest that both Stoned proteins coordi- 
nately function in the recovery of Synaptotagmin I during plasma membrane endocytosis and that removal of the Stoned proteins leads to specific loss of Synaptotagmin I, with consequential profound defects in neurotransmission.

\section{MATERIALS AND METHODS}

Fly stocks. The wild-type strain Oregon-R was used for all control measurements. The homozygous viable stoned allele $\sin ^{\mathrm{C}}$ was used for all third instar analyses. Embryonic lethal stoned alleles $s n^{13-120}$ and $s t n$ PH1 (Fergestad et al., 1999) were used for all embryonic assays. Homozygous mutants were identified by failure to hatch at 22-24 hr after fertilization (AF) and the absence of the FM7 kr-GFP balancer chromosome expression pattern. A transgenic UAS-Synaptotagmin I, $[\mathrm{w}+]$ construct (Littleton et al., 1999) was expressed in the nervous system by use of the neuronal GAL4 drivers 4G (isolated in our lab) and 1407 (Sweeney et al., 1995) using standard techniques (Brand and Perrimon, 1993). The UASSynaptotagmin I construct was also recombined onto $s t n^{\mathrm{C}}$ and $\operatorname{stn}^{13-120}$ chromosomes for overexpression studies of Synaptotagmin in stoned mutant backgrounds. Multiple recombinants were isolated, and the data presented here were pooled from these lines. Vesicle depletion studies were performed using the temperature-sensitive paralytic shibire ${ }^{\mathrm{TS} 1} \mathrm{mu}-$ tation in the Dynamin gene (Kosaka and Ikeda, 1983). All homozygous viable stocks, including shibire ${ }^{\mathrm{TS} 1}$, UAS-Synaptotagmin I, 4G, 1407, and $s n^{\mathrm{C}}$, were maintained and assayed in the homozygous state.

Histology. Immunohistological studies were performed as reported previously (Featherstone et al., 2000). Preparations were incubated overnight at $4^{\circ} \mathrm{C}$ with rabbit polyclonal antisera raised against each of the Stoned proteins, in PBS-TX at 1:2000 (STNA) and 1:500 (STNB) dilutions (Fergestad et al., 1999). Rabbit anti- $\alpha$ Adaptin (Gonzalez-Gaitan and Jackle, 1997) and mouse anti-Dynamin (Developmental Studies Hybridoma Bank, University of Iowa) were used to mark the endocytic regions of the presynaptic terminal (both at 1:500), and mouse antiCysteine String Protein (1:500) (Zinsmaier et al., 1994) was used to label SV domains. All primary antibodies were visualized using Alexa488 anti-rabbit and a rhodamine-conjugated anti-mouse secondary antibody (1:500; Molecular Probes, Eugene, OR). Fluorescent images were acquired on a Bio-Rad Radiance 2000 confocal microscope with a $100 \times$, 1.4 numerical aperture (NA) Plan Apo Nikon oil immersion objective. All images were presented using Adobe Photoshop 5.5 software.

Dye imaging. Staged embryos $\left(22-24 \mathrm{hr}\right.$ after fertilization at $\left.25^{\circ} \mathrm{C}\right)$ and wandering third instar larvae $\left(96-100 \mathrm{hr}\right.$ after hatching at $\left.25^{\circ} \mathrm{C}\right)$ were dissected in calcium-free saline. Saline consisted of (in $\mathrm{mm}$ ): $135 \mathrm{NaCl}$, $5 \mathrm{KCl}, 4 \mathrm{MgCl}_{2}, 5 \mathrm{~N}$-tris[hydroxymethyl]methyl-2-aminoethanesulfonic acid, and 36 sucrose, $\mathrm{pH} 7.15$. Animals were cut dorsally and laid flat on a Sylgard-coated coverslip using a cyanoacrylate glue (Broadie and Bate, 1993). The animals were then minimally dissected, and the gut was removed to expose the ventral neuromusculature. Unless otherwise noted, preparations were incubated with FM1-43 $(10 \mu \mathrm{m}$; Molecular Probes) for $5 \mathrm{~min}$ with high- $\mathrm{K}^{+}$saline $(90 \mathrm{~mm} \mathrm{KCl}$ and $\mathrm{NaCl}$ reduced to $50 \mathrm{~mm}$ ). Specimens were then washed several times with calcium-free saline over $15 \mathrm{~min}$ to remove background. Fluorescent images were acquired on a Bio-Rad Radiance 2000 confocal microscope using a $60 \times$, 1.0 NA Fluor Nikon water immersion objective lens. All images were presented using Adobe Photoshop 5.5 software.

For quantified experiments, all mutant strains were dissected on the same coverslip with wild-type control specimens to ensure that all genotypes were processed exactly equally. Confocal image acquisition settings were identical for all specimens examined in any given experiment, and all values were normalized to the wild-type control. Labeled bouton pixel intensities were quantified using NIH Image software; background staining was subtracted and normalized to control. At least three synaptic boutons ( $>3 \mu \mathrm{m}$ in diameter) were analyzed per neuromuscular junction (NMJ), and three NMJs per animal were pooled. NMJs of muscle 13 were assayed for quantified experiments unless otherwise noted. A minimum of five animals per genotype were examined for a given experiment. Statistical analyses (Mann-Whitney $U$ tests) were done using Instat software (Graph Pad, San Diego, CA).

\section{RESULTS}

\section{Stoned protein colocalization in endocytotic network domains}

Our previous studies suggested that STNA and STNB may act cooperatively to regulate synaptic vesicle recycling events in Dro- sophila (Fergestad et al., 1999). Both proteins localize to the presynaptic compartment and occupy common subsynaptic domains. Recent work from a variety of laboratories has precisely defined spatial and functional domains within synaptic boutons at the Drosophila NMJ. These domains include the active zone, periactive zone, membrane-associated and internal vesicular pools, and a well defined "network" or "lattice" domain that exclusively localizes endocytotic proteins (Estes et al., 1996; Gonzalez-Gaitan and Jackle, 1997; Roos and Kelly, 1999). The endocytotic domain is of particular interest because of our hypothesis that the Stoned proteins mediate vesicular recycling. Previous studies have shown that $\alpha$-Adaptin, a subunit of the endocytotic AP2 Clathrin-associated adapter complex, and Dynamin, the GTPase "pinchase" mediating endocytosis, both localize to the highly characteristic lattice occupying the area surrounding the active zone domains (Gonzalez-Gaitan and Jackle, 1997).

We first determined the localization of STNA and STNB relative to these well defined presynaptic domains. Both STNA and STNB proteins colocalize tightly with the endocytotic proteins $\alpha$-Adaptin and Dynamin (Fig. 1A). All four proteins lie within the endocytotic lattice that surrounds but excludes the exocytotic active zones (Fig. 1A) (Gonzalez-Gaitan and Jackle, 1997; Roos and Kelly, 1999; Teng et al., 1999). Like Dynamin, both STNA and STNB are tightly associated with the plasma membrane and do not occupy cytosolic domains in the bouton interior (Fig. 1A). Markers of the active zone and vesicular pools, such as the SV-associated Cysteine String Protein (CSP), do not colocalize with the Stoned proteins but rather occupy the domains within the endocytotic lattice (Fig. 1B). This confocal analysis supports the localization of both STNA and STNB proteins with the endocytotic network and not with SV pools and areas of exocytosis.

The shibire ${ }^{\text {TS1 }}$ mutation disrupts Dynamin function and provides a temperature-dependent block in the vesicle-budding step of endocytosis (Kosaka and Ikeda, 1983). Stimulation of the Drosophila NMJ in shibire ${ }^{\mathrm{TS} 1}$ mutants at the restrictive temperature $\left(30^{\circ} \mathrm{C}\right)$ depletes the SV population because SVs are driven into the plasma membrane in the absence of endocytosis (Koenig and Ikeda, 1989). Immunological staining of these vesicledepleted shibire ${ }^{\mathrm{TS} 1}$ terminals shows that SV markers, such as CSP, become associated exclusively with the plasma membrane (data not shown) (Estes et al., 1996). We labeled shibire ${ }^{\mathrm{TS} 1}$ SV-depleted terminals with antibodies against STNA, STNB, and $\alpha$-Adaptin. No alteration in the endocytotic network, including the distribution of the Stoned proteins, was observed (data not shown). These studies confirm that both STNA and STNB are associated with the plasma membrane and do not associate with internal vesicles. Returning SV-depleted shibire ${ }^{\mathrm{TS}} 1$ terminals to the nonrestrictive temperature $\left(22^{\circ} \mathrm{C}\right)$ allows endocytosis to resume, resulting in mass membrane retrieval from the plasma membrane (Koenig and Ikeda, 1989; Kuromi and Kidokoro, 1998). After SV depletion $\left(30^{\circ} \mathrm{C}\right.$ for $\left.10 \mathrm{~min}\right)$ and brief recovery to permit massed endocytosis $\left(22^{\circ} \mathrm{C}\right.$ for 10 $\min$ ), we again observed no detectable alteration in the expression pattern of the endocytotic proteins, including both STNA and STNB (data not shown). These data support the conclusion that the Stoned proteins occupy only the endocytotic domain within synaptic boutons and are tightly associated with the plasma membrane. 

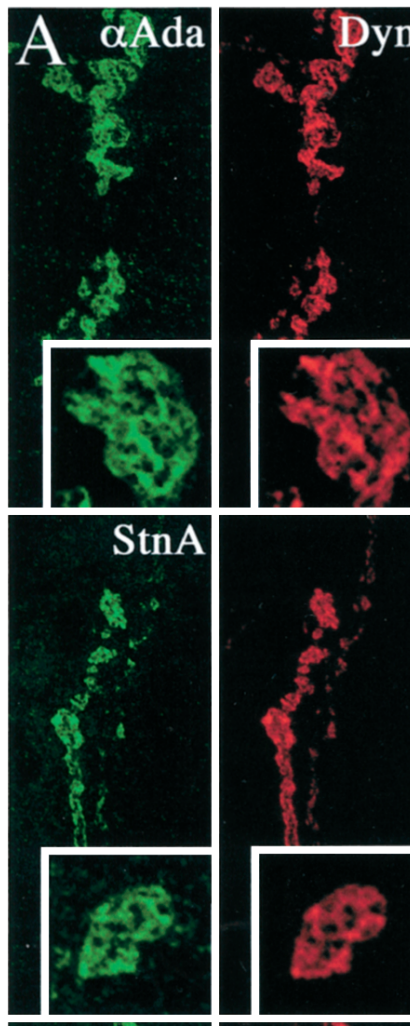

Figure 1. The Stoned proteins STNA and STNB both colocalize with the endocytotic network in presynaptic boutons. $A$, Projected thin optical sections of Drosophila third instar NMJs doublelabeled for STNA $(\operatorname{Stn} A), \operatorname{STNB}(\operatorname{Stn} B)$, or $\alpha$-Adaptin ( $\alpha$ Ada; in green) and Dynamin (Dyn; in red). Right panel shows merged images. $\alpha$-Adaptin, the Stoned proteins, and Dynamin all colocalize in the characteristic lattice network pattern of the endocytotic domain. $B$, NMJs double-labeled for STNA, STNB, or $\alpha$-Adaptin (in green) and SV-associated CSP (in red). Right panel shows merged images. Although the network pattern of $\alpha$-Adaptin and both Stoned proteins exhibits regions of overlapping expression with CSP, CSP is clearly expressed in the exocytotic active zone domains filling the holes in the endocytotic lattice. Magnified boutons are shown in insets. Scale bar, $20 \mu \mathrm{m}$.
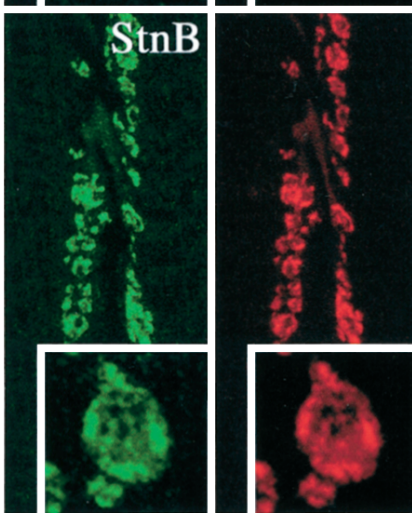
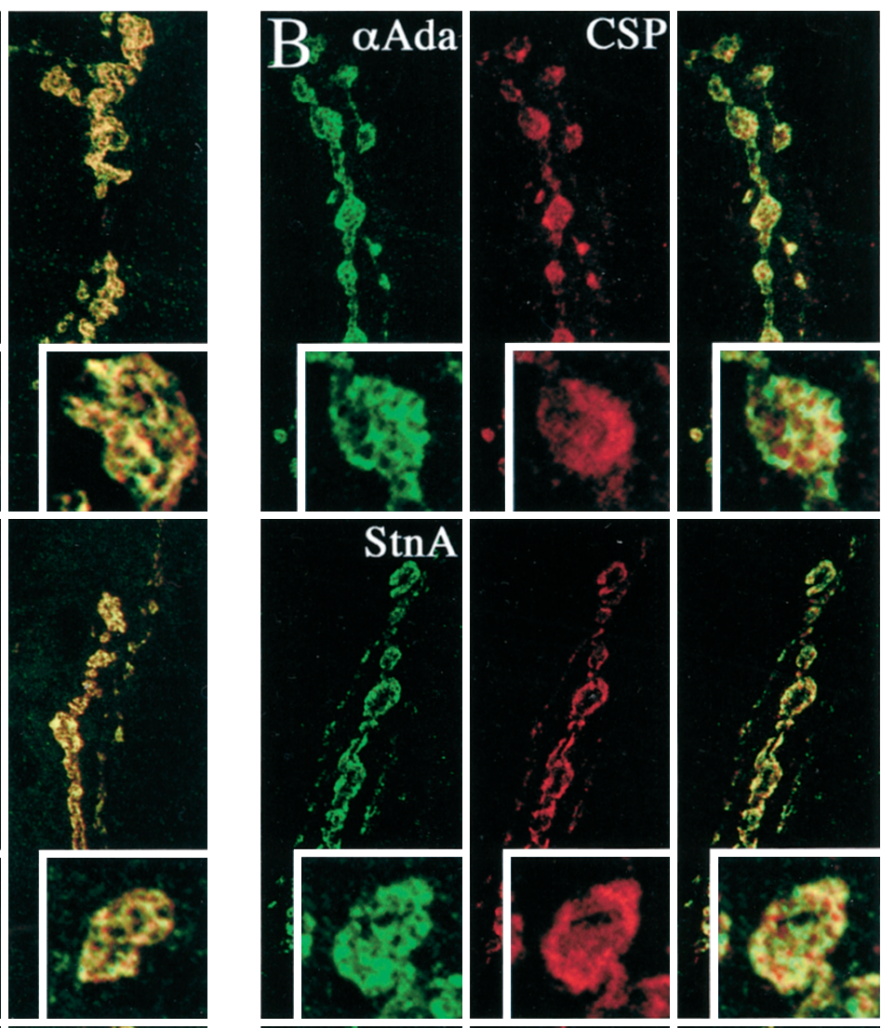

$\operatorname{Stn} \mathrm{A}$
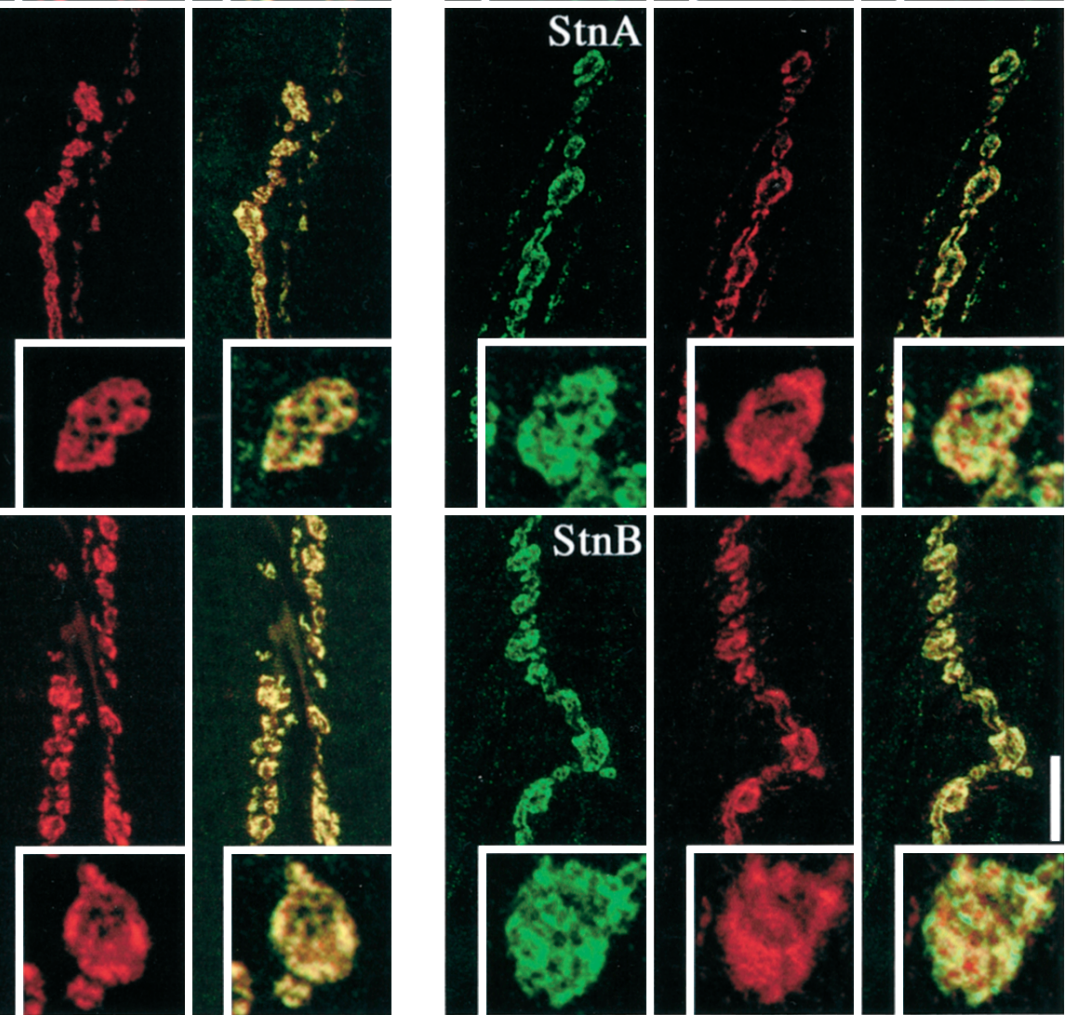

In previous studies, we documented a prominent mislocalization of Synaptotagmin I protein in stoned mutants (Fergestad et al., 1999), showing that stoned function is required to maintain Synaptotagmin I in tight synaptic bouton domains and to prevent its loss throughout the arbor and proximal regions of the axons and its eventual degradation. We wanted to determine whether this relationship was reciprocal by testing whether the Stoned proteins are mislocalized and/or degraded in the absence of Synaptotagmin I. Immunohistochemical studies in $s y t^{\mathrm{AD} 4}$, a null allele of synaptotagmin (Broadie et al., 1994; DiAntonio and Schwarz, 1994), revealed no detectable alteration in either STNA or STNB expression at the embryonic NMJ. Both Stoned proteins were maintained in tight bouton puncta in the complete absence of Synaptotagmin I (data not shown). These data suggest that the Stoned proteins are specifically required for the recycling of Synaptotagmin I but do not require Synaptotagmin I for their localization within the endocytotic domains. Furthermore, these data suggest that the phenotypes observed in synaptotagmin mutants do not result from aberrant localization of the Stoned proteins.

\section{Synapses in stoned mutants display decreased rates of plasma membrane endocytosis}

Our previous studies of stoned mutants documented severely impaired synaptic transmission and a reduced number of morphologically abnormal SVs, suggesting a defect in vesicular recycling at the synapse (Fergestad et al., 1999). To assay for SV recycling defects directly, we used the fluorescent lipophilic dye FM1-43 in membrane retrieval and SV-recycling assays at the NMJ. Extracellularly applied FM1-43 dye is incorporated into $\mathrm{SVs}$ after endocytosis, reliably maintained in SVs and vesicular intermediates, and released during stimulated exocytosis (Betz and Bewick, 1992). Incubating Drosophila larval NMJ preparations with FM1-43 in a depolarizing solution of high $\mathrm{K}^{+}(90 \mathrm{~mm})$ results in specific dye incorporation in SVs of the presynaptic boutons that can be released after subsequent depolarization and fusion (Ramaswami et al., 1994; Kuromi and Kidokoro, 1998). We used this analysis, in various experimental paradigms, to assay endocytosis and SV recycling in stoned mutant NMJs.

Wild-type and stoned mutant third instar animals were dis- 
A
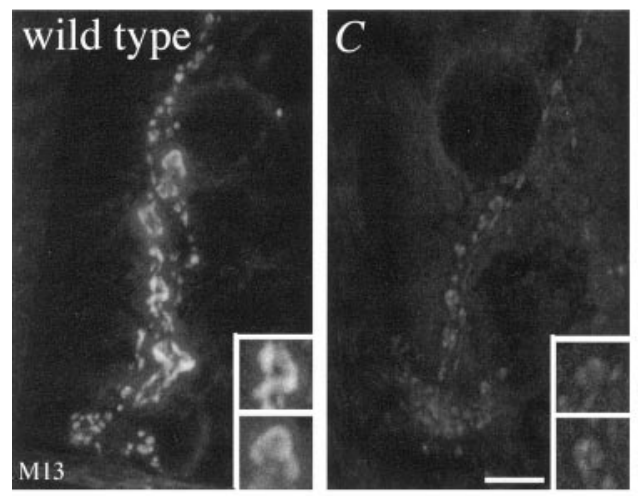

C
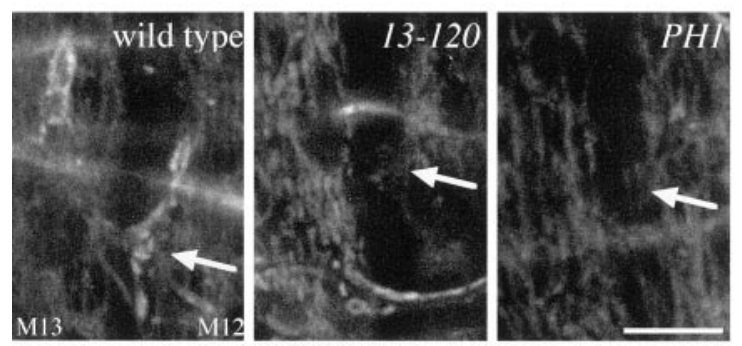

B

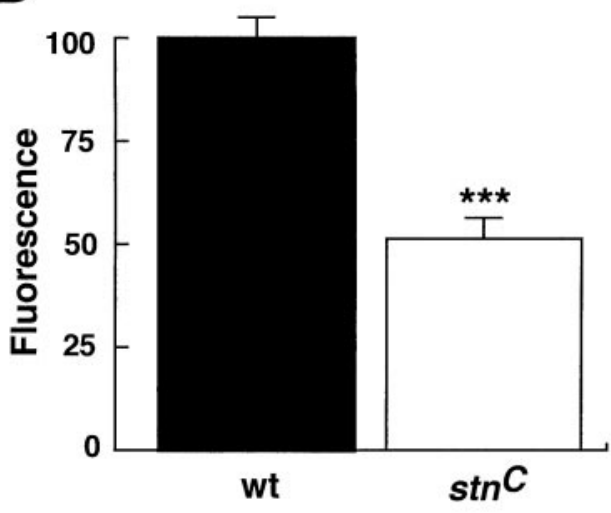

D

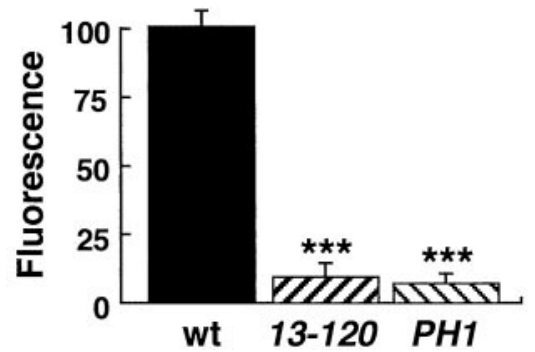

Figure 2. Both viable and embryonic lethal stoned mutant alleles show reduced FM1-43 dye uptake at the Drosophila NMJ. Terminals were loaded with dye by incubating preparations in $90 \mathrm{mM} \mathrm{K}^{+}$saline for $5 \mathrm{~min}$ in the presence of $10 \mu \mathrm{M}$ FM1-43. A, Representative images of FM1-43 labeling in wild-type and $\operatorname{stn}^{\mathrm{C}}$ third instar larval NMJs are shown. Magnified boutons are displayed in insets. $B$, Dye uptake in $\operatorname{stn}^{\mathrm{C}}$ boutons is significantly reduced $(\sim 50 \%)$ compared with that of controls. $C$, Dye loading in wild-type and stoned embryonic NMJ boutons (alleles 13-120, PH1) is shown. Embryos were collected at $22 \mathrm{hr}$ AF and labeled with high- $\mathrm{K}^{+}$saline containing $10 \mu \mathrm{M}$ FM143. NMJs on muscles 12 (M12) and 13 (M13) are displayed; the arrows indicate NMJs on muscle 12. D, Both lethal stoned alleles show a severe defect in dye uptake with fluorescence signals reduced by $>90 \%$. All mutant animals were labeled and imaged together with wild-type animals, and fluorescence was normalized to that of controls. Mann-Whitney $U$ test, $* * * p<0.0001$. $w t$, Wild type. Scale bar: $A, C, 10 \mu \mathrm{m}$. sected in the same chamber and stimulated identically with $5 \mathrm{~min}$ of high-K $\mathrm{K}^{+}$saline in the presence of FM1-43. Control boutons revealed robust endocytosis and strongly incorporated dye, whereas stoned mutant boutons loaded dye very poorly under the same conditions (Fig. 2A). The mean density of FM1-43 incorporation in larval NMJ boutons $(>5 \mu \mathrm{m})$ was quantified and normalized to that of the control. The viable $\operatorname{stn}^{\mathrm{C}}$ mutant animals display a significant impairment $(53 \pm 5 \%$ of control; $p<0.0001)$ in dye uptake (Fig. 2B). Examination of two lethal stoned alleles, $\operatorname{stn}^{13-120}$ and $\operatorname{stn}^{\mathrm{PH} 1}$, revealed an even more profound defect in endocytosis. Because severe stoned mutations are all embryonic lethal (Fergestad et al., 1999), normalized comparisons of FM1-43 dye uptake to control were done at the embryonic NMJ (Fig. 2C). Wild-type embryonic NMJs can be loaded with FM1-43 by high-K ${ }^{+}$depolarization, and all synaptic boutons appear to label, generating a signal comparable with antibody staining against SV proteins at the same stage (21-23 hr AF). In sharp contrast, both lethal stoned alleles showed a $>90 \%$ reduction in dye incorporation, making measurable endocytosis essentially undetectable (Fig. 2D). These studies show that three different alleles of stoned all show severe defects in exo-endo SV recycling at the NMJ synapse and that the severity of the recycling defect correlates with the severity of the mutant allele examined.

Although such a dye uptake impairment implies a direct defect in membrane retrieval, we cannot dismiss the possibility that the reduced exocytosis observed in stoned mutants (Stimson et al., 1998; Fergestad et al., 1999) causes a coupled reduction in endocytosis. To address this possibility, we examined spaced durations of depolarization stimulation and FM1-43 dye loading. Brief dye loading with high $\mathrm{K}^{+}$for $<1 \mathrm{~min}$ (30 sec and 1 min intervals assayed) resulted in a similar defect in stoned dye loading (data not shown; compare with Fig. $2 B$ ). Dye loading with 5 min of stimulation provided a slight increase in bouton fluorescence intensity in both control and mutant NMJ terminals, but the stoned-specific defect in endocytosis remained unaltered (data not shown). Furthermore, $10 \mathrm{~min}$ of high- $\mathrm{K}^{+}$application and dye labeling resulted in no further increase in synaptic dye incorporation of either control or stoned mutant animals, suggesting that the cycling SV pool is maximally saturated after $<5$ min of high-K $\mathrm{K}^{+}$stimulation. Similarly, to determine whether the striking defects in endocytosis in the embryonic lethal mutants were caused by delayed endocytosis, we applied dye for $5 \mathrm{~min}$ in calcium-free saline after 5 min of high- $\mathrm{K}^{+}$stimulation with dye. Longer periods of dye application did not improve the FM1-43 bouton labeling in either wild-type controls or stoned mutants (data not shown). These studies suggest that the recycling SV pool is saturated at these loading times and that stoned mutants have a specific and severe reduction in SV endocytosis. These findings show that the defect in dye uptake is independent of the stimulation duration and probably results from a smaller recycling pool of SVs in stoned mutants.

\section{Synapses lacking Stoned show spatially altered patterns of SV recycling}

Large NMJ boutons (>3 $\mu \mathrm{m}$, typically $3-5 \mu \mathrm{m})$ in normal Drosophila third instar larvae show characteristic patterns of SV pools (Ramaswami et al., 1994). Wild-type boutons loaded with high $\mathrm{K}^{+}$always incorporate FM1-43 dye in a circular pattern with the fluorescence restricted to cortical regions underlying the plasma membrane and an absence of signal in the central regions of the bouton (Fig. 3A). This dye incorporation shows that the recycling SV pool filled via high- $\mathrm{K}^{+}$stimulation is spatially restricted in a characteristic peripheral ring. In contrast, the bouton interior contains a reserve pool of SVs that are accessed only under conditions of intense transmission demand (Kuromi and 
Figure 3. The stoned mutants display altered SV recycling and aberrant spatial localization within synaptic boutons. $A$, High-K ${ }^{+}$FM1-43 loading of third instar NMJs typically results in the labeling of SVs in the periphery of boutons, immediately below the plasma membrane (shown in lower panels). This cortical staining represents the readily releasable SV pool. $B$, Endocytosed dye is quickly dispersed throughout the bouton in $s{ }^{\mathrm{C}}$ animals. Specifically, dye fills the bouton interior (see lower panels) that normally contains the inaccessible reserve SV pool. $C$, FM1-43 is localized to the periphery of the bouton in shibire ${ }^{\mathrm{TS} 1}$ (shiTS1) animals at the permissive temperature $\left(22^{\circ} \mathrm{C}\right.$; shown at left $)$. The exo-endo pool labeling is comparable with that of wild type. $D$, After high- $\mathrm{K}^{+}$stimulation-depletion of all SVs at the shibire ${ }^{\mathrm{TS} 1}$ restrictive temperature $\left(30^{\circ} \mathrm{C}\right)$, synapses were loaded again with dye after returning to the permissive temperature. The resulting mass endocytosis labels both the readily releasable and reserve pools in patterns spatially similar to that of $\operatorname{stn}^{\mathrm{C}}$. Displayed NMJs are all on muscle 12 from the third instar NMJ. Scale bar, $20 \mu \mathrm{m}$.
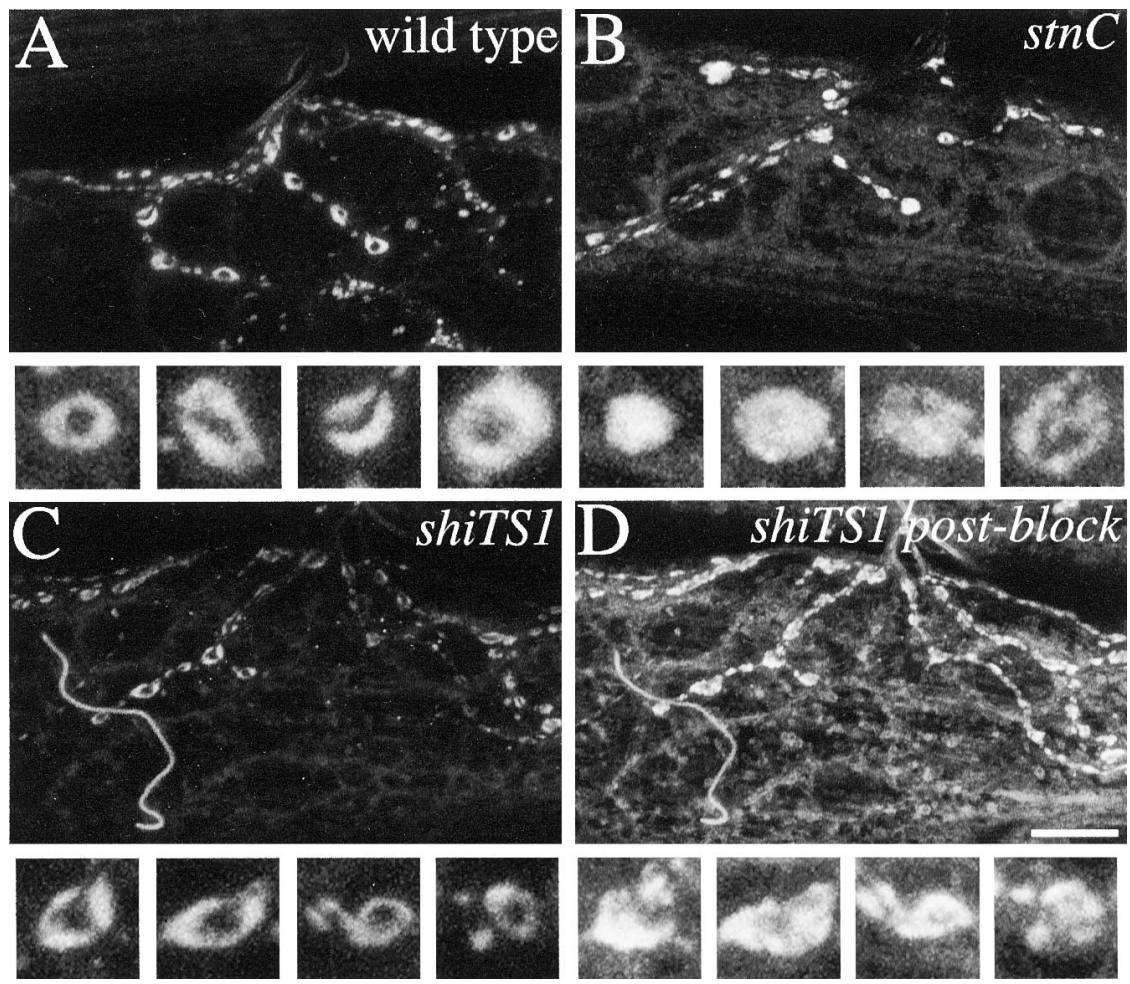

Kidokoro, 1998). Previous studies have shown that the reserve pool can only be loaded with FM1-43 after high-frequency ( $>30$ $\mathrm{Hz})$ stimulation or after complete elimination and mass renewal of the SV population with the Dynamin mutant shibire ${ }^{\mathrm{TS} 1}(\mathrm{Ku}-$ romi and Kidokoro, 1998, 2000). We wanted to determine whether the ready/reserve SV pool boundary is maintained in stoned mutants and whether Stoned proteins may play a role in the spatial dynamics of SV recycling.

In clear contrast to the normal condition, standard high- $\mathrm{K}^{+}$ FM1-43 labeling in $\operatorname{stn}^{\mathrm{C}}$ boutons resulted in the dye filling the entire bouton including the center of the bouton where reserve pool vesicles are normally located (Fig. 3, compare $A, B$ ). Recycled vesicles in stoned mutants lack the normal spatial restriction defining the readily releasable and reserve SV pools. This spatial distribution pattern is reminiscent of the FM1-43 signal after dye uptake in the Dynamin mutant shibire ${ }^{\mathrm{TS} 1}$ (Kuromi and Kidokoro, 1998). After temperature-dependent depletion of all SVs, shibi$r e^{\mathrm{TS} 1}$ animals returned to the permissive temperature undergo mass membrane retrieval coinciding with the formation of early endosomes/cisternae and repopulation of the entire bouton with

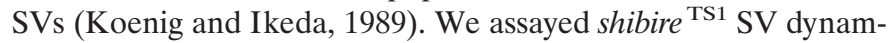
ics by first loading the NMJ terminal at the permissive temperature $\left(22^{\circ} \mathrm{C}\right.$; Fig. $\left.3 C\right)$ and then reloading the same terminal after temperature-dependent $\left(30^{\circ} \mathrm{C}\right)$ depletion of all SVs (Fig. 3D). Before unloading, the shibire ${ }^{\mathrm{TS} 1}$ boutons display a labeled circular pool of SVs corresponding to the readily releasable SV pool identical to that of wild-type controls (Fig. 3, compare $A, C$ ). However, after total SV depletion, shibire ${ }^{\mathrm{TS} 1}$ terminals load both ready and internal reserve pools comparable with the pattern observed in stoned mutants (Fig. 3, compare $B, D$ ). Thus, stoned mutants display aberrant trafficking of newly endocytosed membrane, which may be inappropriately targeted into sorting endosomes in the bouton interior. This conclusion is consistent with the significantly increased incidence of enlarged vesicles and multivesicular bodies we observed previously in stoned mutants at the EM level (Fergestad et al., 1999). This conclusion also supports our hypothesis that loss of stoned function results in increased segregation of membrane and/or protein to the sorting and degradation pathways, at the expense of the recycling SV pool.

\section{Synapses in stoned mutants exhibit slower, but complete, release of FM1-43}

Application of high- $\mathrm{K}^{+}$saline to FM1-43-labeled synaptic boutons results in a second round of exocytosis that releases the dye contained within the SVs (unloading). Terminals loaded with FM1-43 for 5 min release most of this dye via the fast-cycling SV pool after a comparable 5 min unloading period (Fig. $4 A$ ). Under conditions of equal loading and unloading periods, the majority of dye in both wild-type $(85.5 \pm 1.0 \%)$ and $\operatorname{stn}^{\mathrm{C}}(83.7 \pm 5.3 \%)$ NMJ synapses is released via $\mathrm{Ca}^{2+}$-dependent exocytosis (Fig. $4 A$ ). In contrast, shortening unloading times to 1 min of high-K ${ }^{+}$ saline application was still sufficient to unload the majority of dye in wild-type terminals $(88.1 \pm 1.8 \%)$, but the amount of dye released from stoned boutons is significantly reduced $(71.8 \pm$ $3.4 \% ; p=0.0006$; Fig. $4 B)$. These findings confirm that the readily releasable pool is smaller in stoned mutants, and although these vesicles are competent to fuse, they do so in a slower time course. The impairment of dye release is consistent with the defect in exocytosis observed in stoned mutants (Stimson et al., 1998; Fergestad et al., 1999) and may result from the aberrant vesicle trafficking observed in stoned terminals. These data further suggest that the aberrantly distributed SVs in $\operatorname{stn}^{\mathrm{C}}$ mutants are releasable and do not have the "barrier" thought to spatially separate the reserve and ready SV pools (Kuromi and Kidokoro, 1998).

Previously characterized defects in exocytosis and endocytosis suggested that SV maturation in stoned mutants may be impaired (Fergestad et al., 1999). Elegant studies on rat hippocampal cultures have recently estimated the time course for SV matura- 

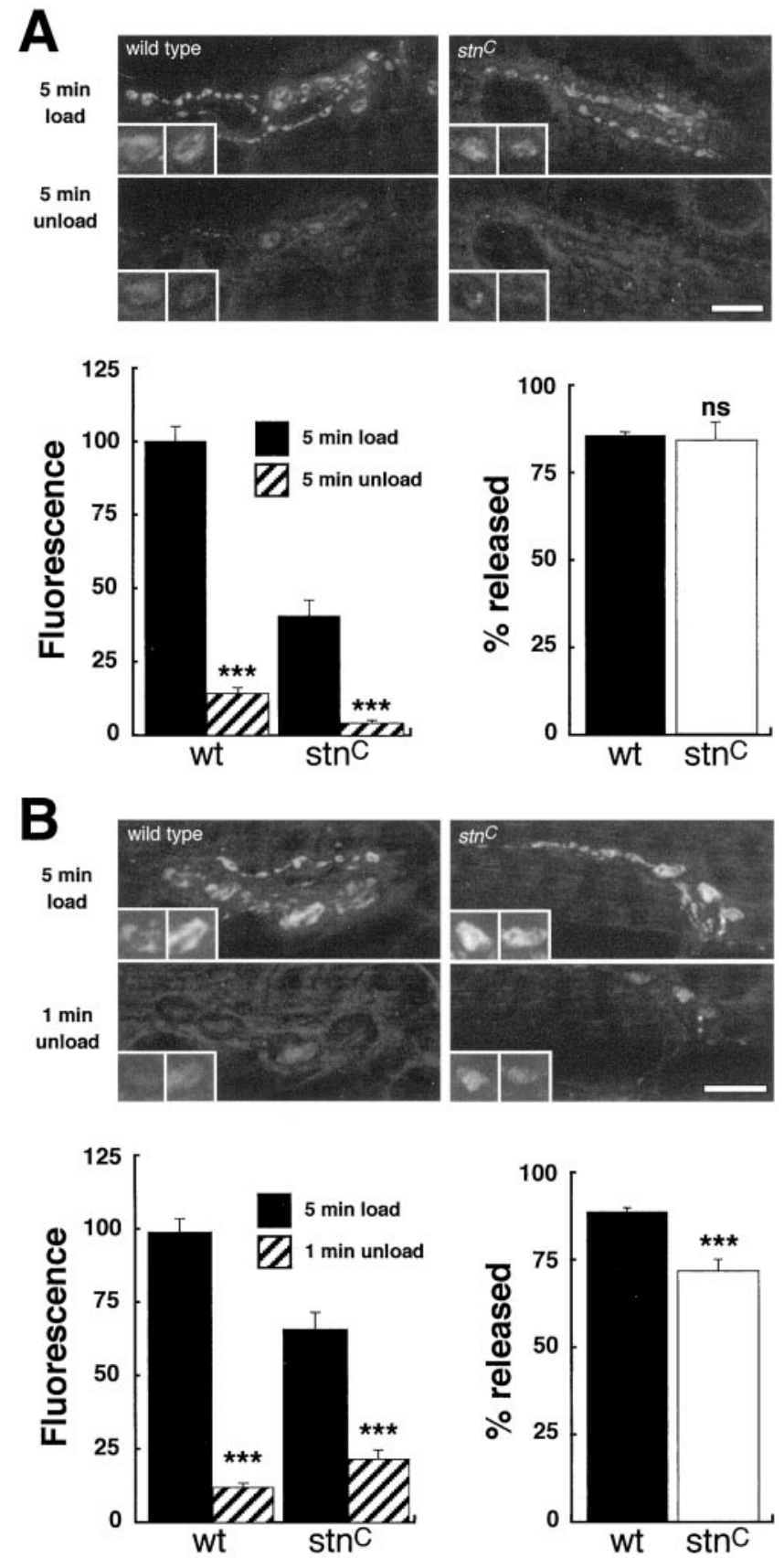

Figure 4. The stoned mutants display delayed SV recycling rates. A, Wild-type and $\operatorname{stn}^{\mathrm{C}}$ third instar NMJs were loaded for 5 min with high-K ${ }^{+}$ depolarization, imaged, and then unloaded with 5 min of high- $\mathrm{K}^{+}$depolarization. Wild-type and $\operatorname{stn}^{\mathrm{C}}$ animals similarly release $\sim 85 \%$ of the loaded dye after a subsequent high- $\mathrm{K}^{+}$stimulation. This shows that the reduced exo-endo SV pool in $s \sin ^{\mathrm{C}}$ is functional and can complete cycling. $B$, One minute of high- $\mathrm{K}^{+}$stimulation unloads wild-type terminals as effectively as 5 min of depolarization (compare with $A$ ). However, significantly less dye is released with shorter unloading times of mutant animals $(\sim 72 \%)$. This shows that the rate of SV recycling is significantly delayed in stoned mutants. Magnified boutons are shown in insets. Mann-Whitney $U$ test, ${ }^{* * *} p<0.0001 . n s$, Not significant. Scale bars, $10 \mu \mathrm{m}$.

tion ("repriming") to be from 5 to 40 sec (Ryan et al., 1993; Ryan and Smith, 1995; Klingauf et al., 1998; Stevens and Wesseling, 1999). To test whether the delay period from endocytosis to exocytosis was increased in stoned mutants, we examined the lapsed time required before loaded dye could be released from
NMJ boutons. FM1-43 dye was loaded with high-K ${ }^{+}$saline (30 sec and 1 and $5 \mathrm{~min}$ ), and then the preparation was washed in calcium-free saline for a variable period ( $\Delta t=0$ and $30 \mathrm{sec}$ and 1 , 5,10 , and $15 \mathrm{~min}$ ) before $\mathrm{K}^{+}$-evoked unloading ( $\Delta t=0$ and $30 \mathrm{sec}$ and 1 and $5 \mathrm{~min})$. No significant change between controls and stoned mutant boutons in the amounts of FM1-43 release was detected in these assays (data not shown). These studies suggest that although fewer SVs are recycled via the endo-exo pool in stoned mutants, no difference in the rate of SV maturation was detectable.

\section{Plasma membrane recycling in stoned mutants is delayed}

Time-lapse studies using FM1-43 dye uptake assays indicate the rates of membrane retrieval after the fusion event to be $\tau_{1 / 2} \sim 20$ sec (Ryan and Smith, 1995) or even faster (Kavalali et al., 1999). To determine whether endocytosis is delayed after exocytosis in stoned mutants we applied FM1-43 either during a $30 \mathrm{sec}$ high- $\mathrm{K}^{+}$stimulus or for $30 \mathrm{sec}$ immediately after the stimulus (Fig. 5) (Ryan, 1999). In wild-type NMJ terminals, a $30 \mathrm{sec}$ application of high- $\mathrm{K}^{+}$saline with FM1-43 loads synaptic terminals to levels similar to those of longer loading times (Fig. 5A), indicating that endocytosis is tightly temporally coupled to exocytosis. FM1-43 application for $30 \mathrm{sec}$ immediately after the stimulation results in much lower levels of dye uptake, indicating that reduced endocytosis continues after the stimulation period (Fig. 5B). In contrast, stoned mutant boutons display greatly reduced endocytosis during the initial time period, when exocytosis and endocytosis levels are normally tightly coupled, and substantial levels of dye uptake only after the depolarizing stimulation. The striking dye uptake difference normally seen between stoned mutants and control animals is no longer present when the dye is added to the preparation after a $30 \mathrm{sec}$ delay $\left(w t=104 \pm 7 ; \operatorname{stn}^{\mathrm{C}}=111 \pm 11 ; p=0.72\right.$; Fig. $\left.5 B\right)$. Because longer dye application times do not allow complete loading, the delay in loading the stoned SV pool cannot alone account for the decreases in overall dye uptake (see Fig. 2). Thus, stoned mutants show both a significantly delayed onset of endocytosis and a significantly smaller recycling SV pool.

\section{Overexpression of Synaptotagmin I rescues the stoned phenotype}

The Stoned proteins and Synaptotagmin I specifically interact in the presynaptic terminal. Both STNA and STNB have been shown to bind Synaptotagmin I directly (Phillips et al., 2000), and Synaptotagmin I is specifically mislocalized and subsequently degraded in stoned mutants (Fergestad et al., 1999). Moreover, the stoned and synaptotagmin mutant phenotypes are strikingly similar; both show comparably decreased and nonsynchronous synaptic transmission, decreased synaptic vesicle density, and aberrant, enlarged synaptic vesicles (Reist et al., 1998; Fergestad et al., 1999). One hypothesis to explain these diverse findings is that the Stoned proteins and Synaptotagmin I mediate the same endocytotic function and that Stoned is required to recruit and/or maintain Synaptotagmin I during plasma membrane endocytosis.

A key prediction of this hypothesis is that elevated levels of Synaptotagmin I should alleviate the severe phenotypes observed in stoned mutants. To test this hypothesis, we used neurally expressing GAL4 drivers to mediate expression of a UAS-Synaptotagmin I transgene construct, thus elevating Synaptotagmin I levels in synaptic boutons (Brand and Perrimon, 1993; Littleton et 

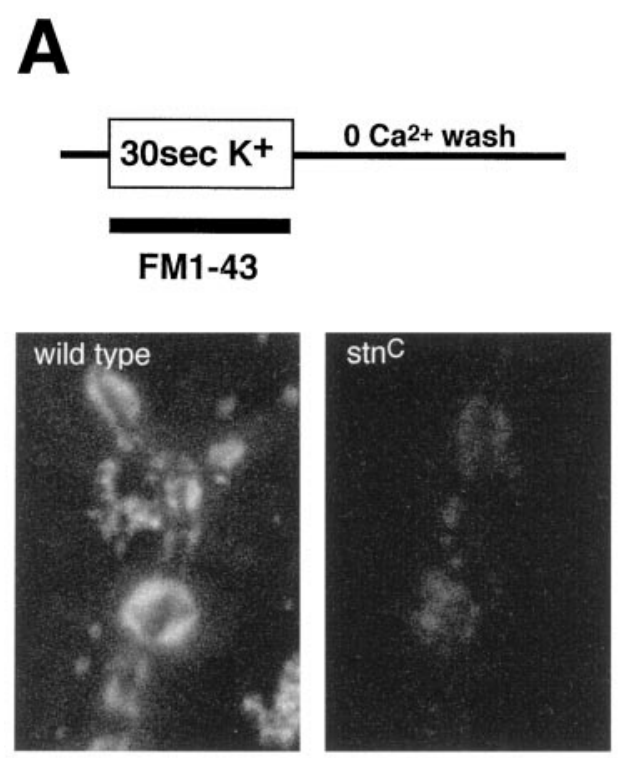

Figure 5. The initiation and rate of SV endocytosis are significantly delayed in stoned mutants. A, FM1-43 was applied with high $\mathrm{K}^{+}$for $30 \mathrm{sec}$ to monitor early endocytosis during depolarization. Representative images of wildtype and $\sin ^{\mathrm{C}}$ third instar NMJs are shown. The $\operatorname{stn}^{\mathrm{C}}$ mutants exhibit striking defects in stimulation-coupled dye loading. $B$, FM1-43 was applied for $30 \mathrm{sec}$ immediately after $30 \mathrm{sec}$ of high- $\mathrm{K}^{+}$saline to monitor delayed endocytosis after exocytosis completion. Representative images show a comparable amount of dye uptake in $s t n^{\mathrm{C}}$ and control animals. Note that images in $B$ were acquired with an increased gain. The different temporal patterns of dye application (horizontal bar) in $A$ and $B$ are shown at top. Each value represents the mean \pm SEM. Mann-Whitney $U$ test, ${ }^{* * *} p<0.0001$. Scale bar, $5 \mu \mathrm{m}$.

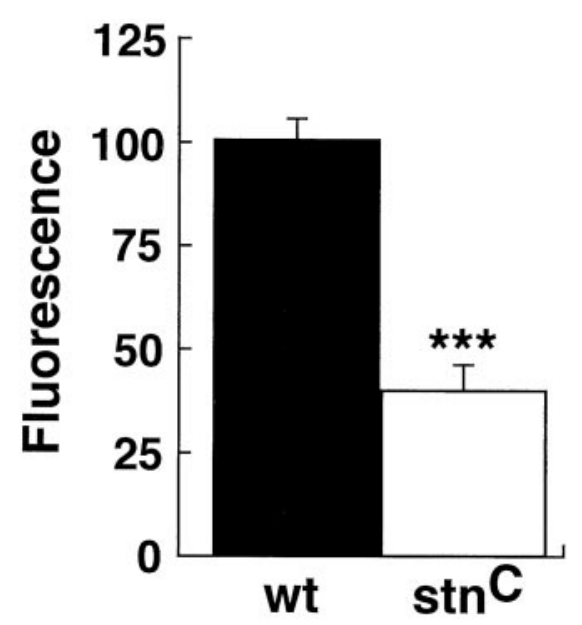

B
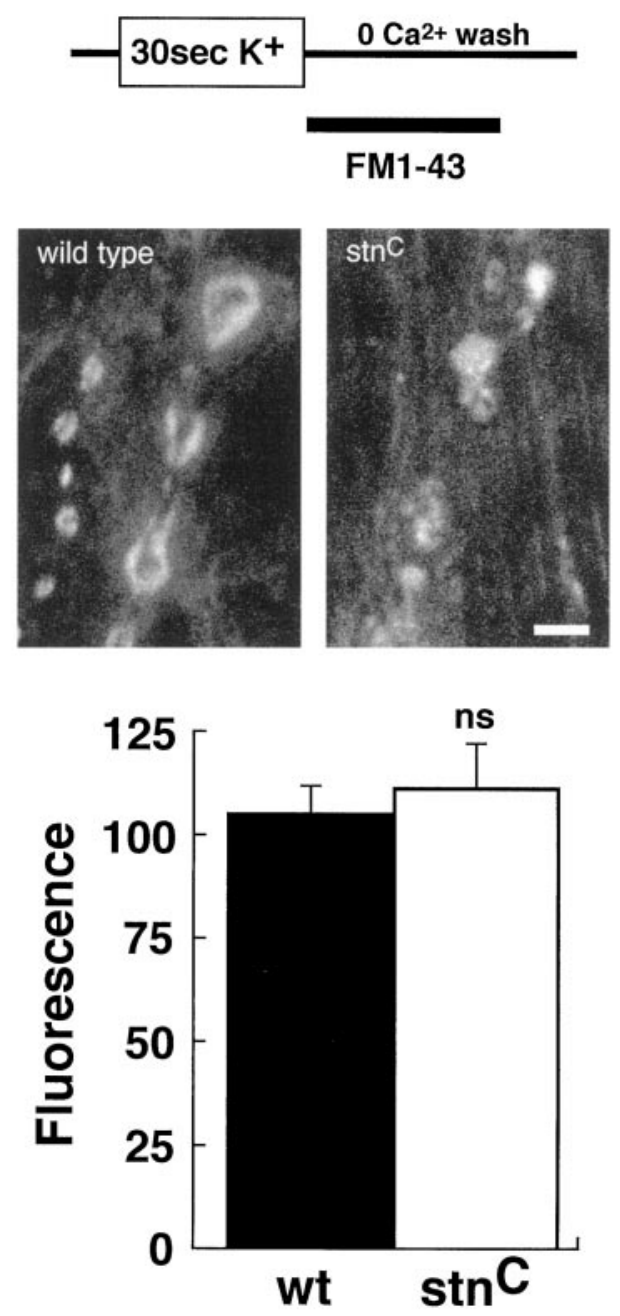

al., 1999). We first tested whether overexpression of Synaptotagmin I in the embryonic lethal stoned mutant background would rescue viability. Homozygous lethal $\operatorname{stn}^{13-120}$ animals, containing the UAS-Synaptotagmin I construct alone, remained embryonic lethal in the absence of a GAL4 driver. However, two temporally different neural GAL4 drivers both rescued the embryonic lethality of $\operatorname{stn}^{13-120}$ in a manner consistent with the onset of their expression. First, the 1407-GAL4 driver expresses throughout the nervous system during embryogenesis (Sweeney et al., 1995) but ceases expression after hatching. When the 1407 driver was crossed to UAS-Synaptotagmin I; $\operatorname{stn}^{13-120}$ animals, mutant animals now hatched $(\sim 98 \%)$ at normal times $(21 \pm 1 \mathrm{hr}$ AF) but then proceed to die as L1 stage larva, consistent with the termination of the 1407 expression. Second, the 4G-GAL4 driver is expressed during later stages of embryogenesis but then remains expressed in the nervous system throughout the life of the animal (K. Bodily and K. Broadie, unpublished observations). When driving Synaptotagmin I expression in $\operatorname{stn}^{13-120}$ mutants with the $4 \mathrm{G}$ driver, embryos also now hatch $(\sim 96 \%)$, although this hatching is delayed (mutant animals now hatch between 21 and $35 \mathrm{hr}$ $\mathrm{AF}$ ), consistent with the later onset of expression. Furthermore, maintained Synaptotagmin I overexpression with $4 \mathrm{G}$ now rescues the embryonic lethal allele $\operatorname{stn}^{13-120}$ to adult viability. These results show that elevated Synaptotagmin I can rescue the stoned lethality and that persistent elevated Synaptotagmin I is required to compensate for the loss of Stoned during maintained synaptic function.

The prediction from these studies is that elevated levels of Synaptotagmin I can alleviate the endocytosis defects caused by stoned mutation. To test this prediction, we assayed FM1-43 dye uptake at the larval NMJ. Overexpression of Synaptotagmin I in $\operatorname{stn}^{\mathrm{C}}$ mutants rescues the endocytotic functional defects observed in $\operatorname{stn}^{\mathrm{C}}$ (Fig. 6A). UAS-Synaptotagmin I; $\operatorname{stn}^{\mathrm{C}}$ larvae without a GAL4 driver are similar to $\operatorname{stn}^{\mathrm{C}}$ mutants alone $\left(\operatorname{stn}^{\mathrm{C}}=52 \pm 5 \%\right.$; UAS-Synaptotagmin, $\operatorname{stn}^{\mathrm{C}}=52 \pm 6 \%$ ) and show no rescue of the dye uptake defect. Strikingly, however, the introduction of the 4G-GAL4 driver almost completely rescues the defects in dye uptake $(90 \pm 7 \%$; no longer significantly different from control; Fig. $6 B$ ). Interestingly, the overexpression of Synaptotagmin I alone in a control background (4G/UAS-Synaptotagmin I) shows a striking increase in the amount of dye loaded (147 \pm $7.0 \% ; p<0.0001$ ) compared with that of controls (Fig. 6). These findings show that the stoned mutant phenotypes can be directly rescued by elevation of Synaptotagmin I levels in the presynaptic terminal. The similarity of the stoned and synaptotagmin mutant phenotypes and the data presented here suggest that the sole role 


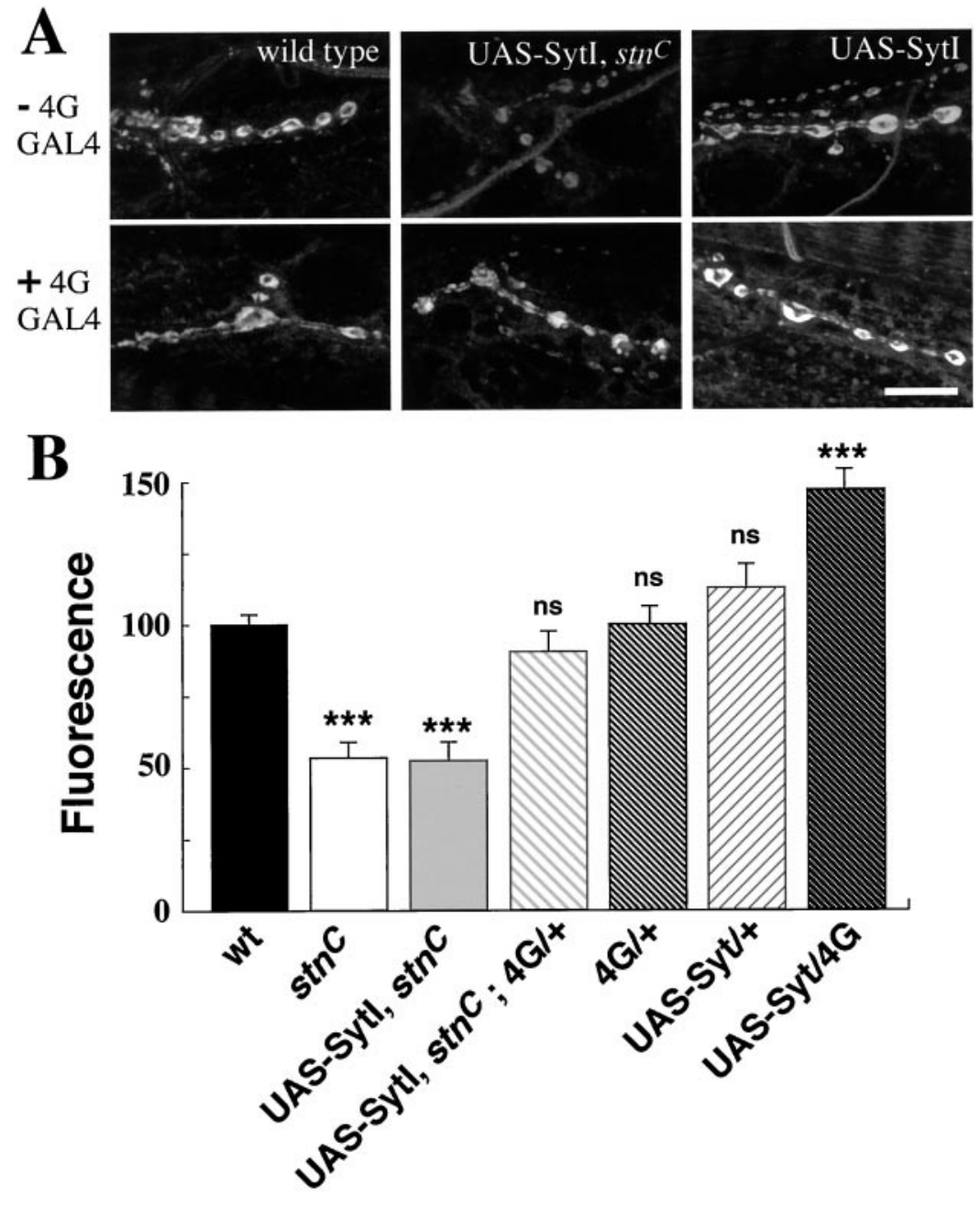

Figure 6. Overexpression of Synaptotagmin I restores the exo-endo pool size in stoned mutants. $A$, Representative images of wild-type, UAS-SytI $s{ }^{\mathrm{C}}{ }^{\mathrm{C}}$, and UAS-SytI third instar NMJ synaptic boutons labeled in the absence and presence of the neuronal 4G-GAL4 driver are shown. $B$, The $\operatorname{stn}^{\mathrm{C}}$ mutant shows a significant $(\sim 50 \%)$ reduction in the amount of FM1-43 uptake during SV recycling. Overexpression of Synaptotagmin I in $\operatorname{stn}^{\mathrm{C}}$ mutants provides a significant increase in dye uptake, returning $\operatorname{stn}^{\mathrm{C}}$ mutant animals to control levels. Overexpression of Synaptotagmin I alone in an otherwise normal genetic background results in a significant $(\sim 50 \%)$ increase in exo-endo SV cycling. Values represent the mean \pm SEM. Mann-Whitney $U$ test, ${ }^{* * *} p<$ 0.0001. Scale bar, $20 \mu \mathrm{m}$.

for the Stoned proteins may be to maintain the presynaptic function of Synaptotagmin I.

\section{DISCUSSION}

\section{The Stoned proteins are required for SV recycling}

The Stoned proteins were originally proposed to act as regulators of SV exocytosis (Stimson et al., 1998). More recently, ultrastructural studies in stoned mutants documented a decreased SV density throughout presynaptic boutons, abnormally large SVs, and an aberrant abundance and distribution of other vesicular intermediates (Fergestad et al., 1999), suggesting a role for the Stoned proteins in SV recycling. The subsynaptic distribution of both STNA and STNB, colocalizing the Stoned proteins with the endocytosis lattice network (Gonzalez-Gaitan and Jackle, 1997; Roos and Kelly, 1998), supports the hypothesis that the Stoned proteins are specifically involved in the endocytosis of SVs from the plasma membrane. In agreement with this hypothesis, the STNA protein contains five DPF motifs ( $\alpha$-Adaptin-interacting motifs; a subunit of AP2), and STNB has a region with strong homology to AP50 (also a subunit of AP2), contains a prolinerich $\mathrm{N}$ terminal (SH3 binding), and has seven NPF motifs (recognizing EH domains) (Andrews et al., 1996; de Beer et al., 1998; Stimson et al., 1998; Owen et al., 1999). STNB is not the Drosophila AP50 homolog, however, because a tightly defined AP50 gene has been characterized by us elsewhere in the Drosophila genome (Zhang and Broadie, 1999). Furthermore, STNA also contains the Clathrin $\beta$-propeller binding motif $\mathrm{LL}(\mathrm{D} / \mathrm{E} /$ $\mathrm{N}) \phi(\mathrm{D} / \mathrm{E})$ and four $\mathrm{Yxx} \phi \mathrm{AP} 2$ binding motifs, and STNB contains 12 Yxx $\phi$ AP2 binding motifs and a (D/E)xxxLL AP2 binding motif, all of which are thought to be involved in organizing the endocytotic machinery (Sengar et al., 1999; Pearse et al., 2000). Together, the molecular nature of the Stoned proteins, their subsynaptic localization, and the stoned mutant phenotypes strongly suggest that the Stoned proteins interact with the endocytotic machinery to mediate SV endocytosis.

\section{SV endocytosis from the plasma membrane depends on the Stoned proteins}

The FM1-43 dye uptake studies presented here demonstrate a specific endocytotic defect in stoned mutants. Both the viable and embryonic lethal stoned alleles have a smaller endo-exo-recycling $\mathrm{SV}$ pool, which is reduced in parallel to the severity of a stoned allelic series. These findings extend and support our ultrastructural analyses at the embryonic NMJ of both embryonic lethal and viable stoned alleles, showing depleted and aberrant presynaptic SV pools (Fergestad et al., 1999), but contrast with an ultrastructural study at the third instar NMJ on the viable $\operatorname{stn}^{\mathrm{C}}$ allele that reported an increase in SV density (Stimson et al., 1998). Because of these paradoxical results, the data presented here suggest that the majority of SVs in the viable allele are not part of the cycling pool and/or are not fusion competent. The spatial localization of endocytosed dye within stoned terminals 
was found throughout the bouton, rather than restricted to the readily releasable SV domain (Kuromi and Kidokoro, 1998). This deficit may be caused by a lack of competent SVs near the active sites, resulting in a mobilization of SVs from the reserve pool near the center of the bouton (Kuromi and Kidokoro, 1998). A shunt of this type could result in recycled SVs being sent to the reserve pool domain in stoned mutants. Similarly, an accumulation of nonfusion competent SVs at the active site might occlude immediate transport of SVs from the endo-exo-cycling pool to the periphery of the bouton. This hypothesis might explain the significant delay in exocytosis in stoned mutants. However, the stoned mutants are capable of eventually exocytosing the FM1-43 marker at levels identical to that of wild-type controls. The release of $\sim 85 \%$ of the loaded dye in stoned mutants suggests that the majority of labeled SVs are capable of subsequent exocytosis. Thus, although exocytosis is delayed in stoned animals and the recycling SV pool is reduced, the limited exo-endo pool can complete its cycle.

Retrieval of SV components from the plasma membrane is tightly temporally coupled to exocytosis $\left(t_{1 / 2}<20 \mathrm{sec}\right)$ (Kavalali et al., 1999). Mutation of stoned disrupts this temporal coupling and delays the onset and rate of endocytosis after exocytosis. Delayed application of FM1-43 to stoned synapses after stimulation reveals that the delayed component of endocytosis is comparable with wild-type levels. There are several possible explanations for these altered endocytosis kinetics in stoned mutants. A likely rationale is that global membrane retrieval is delayed in stoned mutants, suggesting that Stoned proteins may play a role in either initiating endocytosis or facilitating the speed of endocytosis. An alternative scenario may be that there are multiple pathways for SV endocytosis, which differ in temporal kinetics, and that the rapid endocytosis mechanism is specifically impaired in stoned mutants. Although it is formally possible that delays in exocytosis might also explain the delayed membrane retrieval, our previous recordings of synaptic transmission show that exocytosis speed is only very minimally $(<100 \mathrm{msec})$ impaired in stoned mutants (Fergestad et al., 1999).

A specific loss of Synaptotagmin I in stoned mutant synapses, as well as a global degradation and/or loss of Synaptotagmin I, was documented by us previously (Fergestad et al., 1999). Here we show that overexpression of Synaptotagmin I in several stoned alleles rescues lethality and restores synaptic endocytosis function to wild-type levels. This finding is very persuasive for a specific role for the Stoned proteins in recycling and/or maintaining Synaptotagmin I at the synapse. Alternatively, because overexpressing Synaptotagmin I in control animals causes a striking increase in the size of the exo-endo pool, perhaps increasing the levels of Synaptotagmin I results in a general increase in synaptic function that may compensate in some nonspecific way for the depression of transmission in stoned. Curiously, synaptic potential amplitudes were not significantly increased in recordings of Drosophila larvae overexpressing Synaptotagmin I (Littleton et al., 1999). Because increases in the exo-endo pool have been shown to correlate with increases in the quantal content of evoked transmission (Stevens and Sullivan, 1998; Kuromi and Kidokoro, 1999, 2000), this discrepancy may be caused by a technical limitation of the voltage-recording method or saturation of the postsynaptic receptors by increased neurotransmitter release. The fact that both Stoned proteins bind specifically to Synaptotagmin I (Phillips et al., 2000), that Synaptotagmin I is specifically lost from the synapse in stoned mutants (Fergestad et al., 1999), that the ultrastructural and electrophysiological phenotypes of stoned and synaptotagmin mutant animals are strikingly similar (Reist et al., 1998; Fergestad et al., 1999), and that the interaction of synaptotagmin and stoned mutants is lethal (Phillips et al., 2000) strongly argues for the specificity of the Stoned-Synaptotagmin I interaction.

\section{Recycling of Synaptotagmin I requires the Stoned proteins}

How are the numerous different components of the SV recognized and recombined in the precise stoichiometric ratios required for synaptic function? There is an increasing body of evidence that a cast of specific recycling proteins is required to recognize and retrieve specific components of the SV during plasma membrane endocytosis. At center stage, the AP2 complex plays a prominent role in clathrin-mediated SV endocytosis (Cremona and De Camilli, 1997; Hannah et al., 1999). Genetic removal of the $\alpha$-Adaptin subunit in Drosophila shows that the AP2 complex is absolutely required for the SV endocytotic process in this system (Gonzalez-Gaitan and Jackle, 1997). Moreover, the AP2 complex has been shown to bind Synaptotagmin I (Zhang et al., 1994), and it thus seems likely that this complex mediates the endocytotic recovery of Synaptotagmin, likely in addition to other integral SV proteins.

We propose that the role of the Stoned proteins may be to recycle Synaptotagmin I by mediating the association with the AP2 complex. It has been shown recently that both STNA and STNB bind with high specificity to Synaptotagmin I (Phillips et al., 2000) and therefore likely act in a cooperative manner in Synaptotagmin I retrieval. Studies by Haucke and De Camilli (1999) have shown that the AP2-Synaptotagmin I interaction can be stimulated by the presence of Yxx $\phi$-containing peptides, which also enhance the recruitment of AP2 to the plasma membrane. Because both Stoned proteins contain multiple copies of these tyrosine-based motifs, as well as other AP2 and Clathrin binding domains (see above), we hypothesize that the Stoned proteins specifically promote the retrieval of Synaptotagmin I from the plasma membrane by mediating the AP2-Synaptotagmin I binding. Because the Stoned proteins are encoded by a dicistronic locus, polarity constraints have to date prevented an independent dissection of the roles of STNA and STNB in Synaptotagmin I endocytosis. Why does the process require two proteins, and what does each contribute to the recycling mechanism? Targeted homologous knock-out techniques are being used to explore these questions (Rong and Golic, 2000).

As the proposed calcium sensor for SV fusion, Synaptotagmin is likely to function as a key regulator of transmission strength. The number of Synaptotagmin proteins in a SV membrane may play an important role in regulating the response of the presynaptic terminal to depolarizing stimuli (Littleton et al., 1999). We have shown here that overexpression of Synaptotagmin I alone is capable of substantially increasing the size of the endo-exo SV pool. Therefore, the Stoned proteins, by regulating Synaptotagmin I recycling, also act as key regulators of neurotransmission strength. Future experiments are focusing on the specific regulation of Synaptotagmin I levels by each of the Stoned proteins.

\section{REFERENCES}

Andrews J, Smith M, Merakovsky J, Coulson M, Hannan F, Kelly LE (1996) The stoned locus of Drosophila melanogaster produces a dicistronic transcript and encodes two distinct polypeptides. Genetics 143:1699-1711.

Betz WJ, Bewick GS (1992) Optical analysis of synaptic vesicle recycling at the frog neuromuscular junction. Science 255:200-203.

Brand AH, Perrimon N (1993) Targeted gene expression as a means of 
altering cell fates and generating dominant phenotypes. Development 118:401-415.

Broadie K, Bellen HJ, DiAntonio A, Littleton JT, Schwarz TL (1994) Absence of synaptotagmin disrupts excitation-secretion coupling during synaptic transmission. Proc Natl Acad Sci USA 91:10727-10731.

Broadie KS, Bate M (1993) Development of the embryonic neuromuscular synapse of Drosophila melanogaster. J Neurosci 13:144-166.

Ceccarelli B, Hurlbut WP (1980) $\mathrm{Ca}^{2+}$-dependent recycling of synaptic vesicles at the frog neuromuscular junction. J Cell Biol 87:297-303.

Ceccarelli B, Hurlbut WP, Mauro A (1973) Turnover of transmitter and synaptic vesicles at the frog neuromuscular junction. J Cell Biol 57:499-524.

Cremona O, De Camilli P (1997) Synaptic vesicle endocytosis. Curr Opin Neurobiol 7:323-330.

de Beer T, Carter RE, Lobel-Rice KE, Sorkin A, Overduin M (1998) Structure and Asn-Pro-Phe binding pocket of the Eps15 homology domain. Science 281:1357-1360.

DiAntonio A, Schwarz TL (1994) The effect on synaptic physiology of synaptotagmin mutations in Drosophila. Neuron 12:909-920.

Estes PS, Roos J, van der Bliek A, Kelly RB, Krishnan KS, Ramaswami M (1996) Traffic of dynamin within individual Drosophila synaptic boutons relative to compartment-specific markers. J Neurosci 16:5443-5456.

Featherstone DE, Rushton EM, Hilderbrand-Chae M, Phillips AM, Jackson FR, Broadie K (2000) Presynaptic glutamic acid decarboxylase is required for induction of the postsynaptic receptor field at a glutamatergic synapse. Neuron 27:71-84.

Fergestad T, Davis WS, Broadie K (1999) The stoned proteins regulate synaptic vesicle recycling in the presynaptic terminal. J Neurosci 19:5847-5860.

Gonzalez-Gaitan M, Jackle H (1997) Role of Drosophila alpha-adaptin in presynaptic vesicle recycling. Cell 88:767-776.

Hannah MJ, Schmidt AA, Huttner WB (1999) Synaptic vesicle biogenesis. Annu Rev Cell Dev Biol 15:733-798.

Haucke V, De Camilli P (1999) AP-2 recruitment to synaptotagmin stimulated by tyrosine-based endocytic motifs. Science 285:1268-1271.

Heuser JE, Reese TS (1973) Evidence for recycling of synaptic vesicle membrane during transmitter release at the frog neuromuscular junction. J Cell Biol 57:315-344.

Heuser JE, Reese TS (1981) Structural changes after transmitter release at the frog neuromuscular junction. J Cell Biol 88:564-580.

Jorgensen EM, Hartwieg E, Schuske K, Nonet ML, Jin Y, Horvitz HR (1995) Defective recycling of synaptic vesicles in synaptotagmin mutants of Caenorhabditis elegans. Nature 378:196-199.

Kavalali ET, Klingauf J, Tsien RW (1999) Properties of fast endocytosis at hippocampal synapses. Philos Trans R Soc Lond [Biol] 354:337-346.

Klingauf J, Kavalali ET, Tsien RW (1998) Kinetics and regulation of fast endocytosis at hippocampal synapses. Nature 394:581-585.

Koenig JH, Ikeda K (1989) Disappearance and reformation of synaptic vesicle membrane upon transmitter release observed under reversible blockage of membrane retrieval. J Neurosci 9:3844-3860.

Koenig JH, Ikeda K (1996) Synaptic vesicles have two distinct recycling pathways. J Cell Biol 135:797-808.

Kosaka T, Ikeda K (1983) Possible temperature-dependent blockage of synaptic vesicle recycling induced by a single gene mutation in Drosophila. J Neurobiol 14:207-225.

Kuromi H, Kidokoro Y (1998) Two distinct pools of synaptic vesicles in single presynaptic boutons in a temperature-sensitive Drosophila mutant, shibire. Neuron 20:917-925.

Kuromi H, Kidokoro Y (1999) The optically determined size of exo/ endo cycling vesicle pool correlates with the quantal content at the neuromuscular junction of Drosophila larvae. J Neurosci 19:1557-1565.

Kuromi H, Kidokoro Y (2000) Tetanic stimulation recruits vesicles from reserve pool via a cAMP-mediated process in Drosophila synapses. Neuron 27:133-143

Littleton JT, Serano TL, Rubin GM, Ganetzky B, Chapman ER (1999) Synaptic function modulated by changes in the ratio of synaptotagmin I and IV. Nature 400:757-760.
Murthy VN, Stevens CF (1998) Synaptic vesicles retain their identity through the endocytic cycle. Nature 392:497-501.

Nonet ML, Holgado AM, Brewer F, Serpe CJ, Norbeck BA, Holleran J, Wei L, Hartwieg E, Jorgensen EM, Alfonso A (1999) UNC-11, a Caenorhabditis elegans AP180 homologue, regulates the size and protein composition of synaptic vesicles. Mol Biol Cell 10:2343-2360.

Owen DJ, Vallis Y, Noble ME, Hunter JB, Dafforn TR, Evans PR, McMahon HT (1999) A structural explanation for the binding of multiple ligands by the alpha-adaptin appendage domain. Cell 97:805-815.

Palfrey HC, Artalejo CR (1998) Vesicle recycling revisited: rapid endocytosis may be the first step. Neuroscience 83:969-989.

Pearse BM, Smith CJ, Owen DJ (2000) Clathrin coat construction in endocytosis. Curr Opin Struct Biol 10:220-228.

Phillips AM, Smith M, Ramaswami M, Kelly LE (2000) The products of the Drosophila stoned locus interact with synaptic vesicles via synaptotagmin. J Neurosci 20:9000-9011.

Ramaswami M, Krishnan KS, Kelly RB (1994) Intermediates in synaptic vesicle recycling revealed by optical imaging of Drosophila neuromuscular junctions. Neuron 13:363-375.

Reist NE, Buchanan J, Li J, DiAntonio A, Buxton EM, Schwarz TL (1998) Morphologically docked synaptic vesicles are reduced in synaptotagmin mutants of Drosophila. J Neurosci 18:7662-7673.

Rong YS, Golic KG (2000) Gene targeting by homologous recombination in Drosophila. Science 288:2013-2018.

Roos J, Kelly RB (1998) Dap160, a neural-specific Eps15 homology and multiple SH3 domain-containing protein that interacts with Drosophila dynamin. J Biol Chem 273:19108-19119.

Roos J, Kelly RB (1999) The endocytic machinery in nerve terminals surrounds sites of exocytosis. Curr Biol 9:1411-1414.

Ryan TA (1999) Inhibitors of myosin light chain kinase block synaptic vesicle pool mobilization during action potential firing. J Neurosci 19:1317-1323.

Ryan TA, Smith SJ (1995) Vesicle pool mobilization during action potential firing at hippocampal synapses. Neuron 14:983-989.

Ryan TA, Reuter H, Wendland B, Schweizer FE, Tsien RW, Smith SJ (1993) The kinetics of synaptic vesicle recycling measured at single presynaptic boutons. Neuron 11:713-724.

Sengar AS, Wang W, Bishay J, Cohen S, Egan SE (1999) The EH and SH3 domain Ese proteins regulate endocytosis by linking to dynamin and Eps15. EMBO J 18:1159-1171.

Stevens CF, Sullivan JM (1998) Regulation of the readily releasable vesicle pool by protein kinase C. Neuron 21:885-893.

Stevens CF, Wesseling JF (1999) Identification of a novel process limiting the rate of synaptic vesicle cycling at hippocampal synapses. Neuron 24:1017-1028.

Stimson DT, Estes PS, Smith M, Kelly LE, Ramaswami M (1998) A product of the Drosophila stoned locus regulates neurotransmitter release. J Neurosci 18:9638-9649.

Sweeney ST, Broadie K, Keane J, Niemann H, O'Kane CJ (1995) Targeted expression of tetanus toxin light chain in Drosophila specifically eliminates synaptic transmission and causes behavioral defects. Neuron 14:341-351.

Teng H, Cole JC, Roberts RL, Wilkinson RS (1999) Endocytic active zones: hot spots for endocytosis in vertebrate neuromuscular terminals. J Neurosci 19:4855-4866.

von Poser C, Zhang JZ, Mineo C, Ding W, Ying Y, Sudhof TC, Anderson RGW (2000) Synaptotagmin regulation of coated pit assembly. J Biol Chem 275:30916-30924.

Zhang JZ, Davletov BA, Sudhof TC, Anderson RG (1994) Synaptotagmin I is a high affinity receptor for clathrin AP-2: implications for membrane recycling. Cell 78:751-760.

Zhang YQ, Broadie K (1999) Cloning, mapping and tissue-specific expression of Drosophila clathrin-associated protein AP50 gene. Gene 233:171-179.

Zinsmaier KE, Eberle KK, Buchner E, Walter N, Benzer S (1994) Paralysis and early death in cysteine string protein mutants of Drosophila. Science 263:977-980. 